\title{
Ağır Hizmet Araçlarında Kullanılan Z-Kam Kampanalı Fren Tork Plakası Ağırlık Optimizasyonu
}

\author{
*1'ibrahim Can Güleryüz and ${ }^{2}$ Barış Yılmaz \\ ${ }^{*}{ }^{1}$ Ege Fren Sanayii ve Ticaret A.Ş., Izmir, Turkey \\ ${ }^{2}$ Ege Fren Sanayii ve Ticaret A.Ş., Izmir, Turkey
}

\section{Özet}

Teknoloji geliştikçe, yakıt tüketiminin ve araç emisyonlarının iyileştirilmesi için başarımdan ödün vermeden araç ağırlığının azaltılması önemli bir alan haline gelmektedir. Bir araçta yaylanmayan kütlenin azaltılma olasılığı, aks ve tekerlek ucu bileşenlerinin ağılık optimizasyonu ile ilgili birçok araştırmanın odak noktası olmaktadır. Bu çalışmada, ağır hizmet araçlarında kullanılan Z-kam kampanalı frenin ana parçası olan tork plakasının mekanik tasarımı topoloji optimizasyonu ve sonlu elemanlar (SE) yöntemleri kullanılarak gerçekleştirilmiştir. İlk olarak, kritik gerilme bölgelerinin ve seviyelerinin tespiti için orijinal tork plakasının SE analizi gerçekleştirilmiştir. Daha sonra, belirlenen sınır koşulları altında orijinal tork plakasının topoloji optimizasyonu gerçekleştirilmiştir. İhtiyaç duyulmayan hacimler ve üretilebilirlik kısıtlamaları göz önünde bulundurularak yeni bir tork plakası tasarımı oluşturulmuştur. Son olarak, final tasarımın doğrulanması için SE analizleri tekrarlanmıştır. Gerilme seviyelerindeki belirgin düşüşe ek olarak, döküm ve işlenmiş parça ağırlıklarında sırasıyla \% 11,9 ve $\% 12,2$ azalma sağlanmıştır.

Anahtar kelimeler: Tork plakası, topoloji optimizasyonu, sonlu elemanlar (SE) analizi, Z-kam kampanalı fren, ağır hizmet aracı.

\section{Weight Optimization of Torque Plate of Z-cam Drum Brake Used In Heavy Duty Vehicles}

\begin{abstract}
As the technology develops, the reducing vehicle weight without compromising performance becomes an area, which is important to improve fuel consumption and vehicle emissions. The possibility of reducing the unsprung mass in a vehicle is the focus of many investigations on weight optimization of axle and wheel-end components. In this study, mechanical design of a torque plate, which is one of the main parts of a Z-cam drum brake used in heavy-duty vehicles, was conducted by using topology optimization and finite element (FE) methods. Firstly, FE analysis of the original torque plate was conducted to determine critical stress levels and locations. After that, topology optimization was carried out on the original torque plate for specified boundary conditions. Taking redundant volume and manufacturability constraints into account a new torque plate design was composed. Finally, FE analysis was repeated to verify the final design. Addition to the significant decrease in stress levels, reduction in casting and machined part masses by $11.9 \%$ and $12.2 \%$ were achieved.
\end{abstract}

Key words: Torque plate, topology optimization, finite element (FE) analysis, Z-cam drum brake, heavy duty vehicle.

*Corresponding author: Address: Ege Fren Sanayii ve Ticaret A.Ş., 7405/2 Sokak No:4 Pınarbaş1, 35060, Izmir TURKEY. E-mail address: can.guleryuz@egefren.com.tr, Phone: +902323973736 


\section{Giriş}

Fren sistemi bir aracın kontrol ve emniyetini temin eden sistemlerin başında gelmektedir. Fren sistemi aracın hızını yavaşlatmak, araç hızını yokuş aşağı yollarda sabit tutmak veya duran bir aracın kendi kendine harekete geçmesini önlemek amacıyla tasarlanmıştır [1]. Tekerlek freni olarak sürtünme tabanlı frenler kullanılır. Doğrudan doğruya dingil ucuna (tekerlek içerisine) veya tahrik mili üzerine yerleştirilen sürtünme tabanlı tekerlek frenleri ihtiyaç duyulan fren momentini oluşturmak, sürtünme yoluyla mekanik enerjinin 1sı enerjisine dönüştürerek atılması görevini yerine getirirler [2].

Karayolu araçlarında yaygın olarak kampanalı ve disk frenler olmak üzere iki farklı sürtünme tabanlı fren grubu bulunmaktadır. Disk frenlerde, dönen diskin her iki tarafına konumlandırılan sürtünme elemanı olan balataların fren diskine yaslanması ile sürtünme sonucu frenleme gerçekleşirken; kampanalı frenlerde pabuçlara monte edilen balataların dışa doğru açılarak kampanaya ait iç silindir yüzeyi ile sürtünmesi sonucunda frenleme meydana gelir [3]. Yeni nesil binek araçlarda ön aksta disk fren uygulaması yer almakla birlikte; arka aks uygulamalarında da disk fren tercih edilmektedir [4]. Son 20 yıldaki ağır ticari araç uygulamalarında, Avrupa'daki disk fren eğilimi artmasına karşılık; Kuzey Amerika ve dünyanın geri kalanında kamalı, S-kam ve Zkam tipi kampanalı frenler hala yaygın olarak tercih edilmektedir [5]. Kampanalı frenler; şantiye araçları, askeri araçlar ve treyler uygulamalarında yaygın olarak yer almaktadır.

Araç ağırlığının azaltılmasına yönelik çalışmalar, $\mathrm{CO}_{2}$ emisyonu ve yakıt sarfiyatının azaltılmasında önemli bir rol oynadığı için otomotivde birçok çalışmanın odak noktası olmuştur [6]. Bu nedenle literatürde özellikle yaylanmayan araç kütlesini oluşturan dingil ve dingil ucu komponentleri olan dingil, kovan, alt ve üst salıncak kolları, kampanalı ve disk fren alt parçalarının hafifletilmesine yönelik sayısal çalışmalara ağırlık verildiği görülmektedir [7-15]. Bu nedenle, bu çalışmada ağır hizmet araçlarında kullanılan Z-kam kampanalı frenin ana parçası olan tork plakasının mekanik tasarımı topoloji optimizasyonu ve sonlu elemanlar (SE) yöntemleri kullanılarak ele alınmıştır.

Literatürde, kampanalı fren tork plakası ağırlık optimizasyonu konusu ile ilgili yer bulan çalışmalar [12-13] ile sınırlıdır. Yücel ve arkadaşları, ağır hizmet araçlarında kullanılan S-kam kampana fren tork plakasının ağırlık optimizasyonu çalışmasını gerçekleştirmiştir. Tork plakasına etkiyen hizmet yüklerinin ve S-kam fren faktörünün belirlenebilmesi için vektör analizi yapılmıştır. Vektör analizinde elde edilen hizmet yükleri kullanılarak mevcut S-kam fren tork plakasının SE analizleri gerçekleştirilerek, kritik gerilme lokasyonları belirlenmiştir. Mevcut tork plakasının topoloji optimizasyonunu gerçekleştirilerek, tork plakası üzerinde ihtiyaç duyulmayan bölümler saptanmıştır. Döküm ve işleme prosesleri de göz önünde bulunarak, final tork plakası tasarımı oluşturulmuştur. Tasarım doğrulama amacıyla, final tasarımın SE analizleri gerçekleştirilmiştir. Sayısal çalışmanın sonucunda, mekanik dayanımdan ödün vermeden tork plakası ağırlığında \%18,59 oranında bir ağırlık optimizasyonu elde edilmiştir [12]. Güleryüz ve Yılmaz'ın gerçekleştirdiği çalışmada, ağır hizmet araçlarına kullanılan Z-kam kampanalı fren tork plakasının ağırlık optimizasyonu, Yücel ve arkadaşlarının önerdiğine benzer bir sistematik kullanılarak ele alınmıştır [13]. Literatürdeki diğer kampanalı frenler ile ilgili çalışmalar, fren başarımına etkiyen kampanalı fren değişkenlerinin iyileştirilmesi ve optimizasyonuna yöneliktir [5, 14-15]. 
Çalışmanın genel düzeni şu şekildedir: Bölüm 2'de orijinal Z-kam tork plakasının SE analizleri gerçekleştirilmiştir. Bölüm 3'de mevcut tork plakasının belirlenen sınır koşulları altındaki topoloji optimizasyonu ele alınmaktadır. Topoloji optimizasyonu sonuçları ve üretilebilirlik kısıtları göz önünde bulundurularak, yeni tork plakası tasarımı oluşturulmuştur. Tasarım doğrulama amaciyla, final tasarımın SE analizleri gerçekleștirilmiştir. Bölüm 4'te SE ve topoloji optimizasyonu sonuçlarına ilişkin detaylar özetlenmektedir. Sonuç bölümü çalışmanın genel sonucunu içermektedir.

SE analizlerine başlamadan önce, Z-kam kampanalı fren ve alt parçalarının kullanımını ve çalışma prensibinin anlaşılması önemlidir. Z-kam fren montajı temel olarak levye, mil, itici pimler, karşılayan ve yaslanan pabuçlar, C-yayı, ayar cıvataları, tork plakası, toz sacı, braket ve otomatik boşluk ayarı mekanizması alt parçalarından meydana gelmektedir. Şekil 1'de Z-kam kampanalı fren alt parçalarının patlatılmış ve tork plakası üzerine montajlı görünümleri verilmektedir. Her iki pabuç ve diğer Z-kam fren alt parçaları tork plakası diğer bir adıyla fren tablası üzerine monte edilerek; araca ait aksona ya da aks flanşına cıvatalar yardımıyla bağlanmaktadır.

Fren körüğündeki basınçlandırılmış havanın oluşturduğu mekanik itici mil kuvveti; ayar cıvataları, itici pimler, mil ve levye üzerinden pabuçlara iletilir. Pabuçlar, ayar cıvataları ile mekanik olarak tahrik edilirken tork plakasındaki pabuç mesnet yüzeyleri üzerinde serbestçe kayar. Ayar cıvatasının stroğu balata aşınması ya da frenleme sonucunda kampananın ısıya bağlı genleşmesi nedeniyle artar. Balata ve kampana arasındaki boşluk, otomatik boşluk ayarlayıcı mekanizma tarafindan sabit tutulur. Fren körüğü stroğu belirli bir limit değeri aştığında, körük karakteristiğine bağlı olarak körük kuvveti ve pabuçlara iletilen kuvvet hızla düşer.

Kampananın dönme yönü ve pabuçların dönme eğilimine bağlı olarak, yaslanan pabuçta kampana dönme yönünde bir döndürme momenti oluşurken; karşllayan pabuçta kampana dönme yönünün tersinde bir döndürme momenti oluşmaktadır [16]. Şekil 3'de kampana dönüş yönüne göre yaslanan ve karşılayan pabuç tanımlamaları yapılmaktadır.
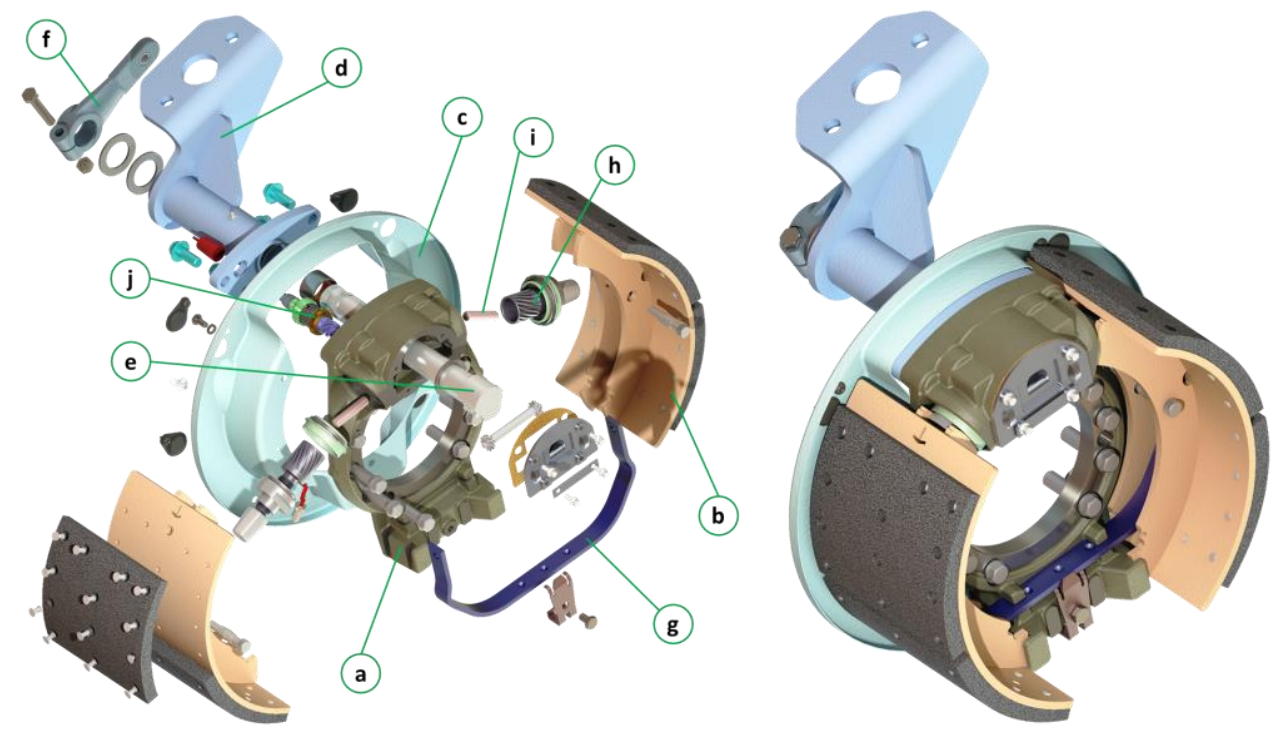

Şekil 1. Z-kam kampanalı fren: (a) Tork plakası, (b) Pabuçlar, (c) Toz sacı, (d) Braket, (e) Mil, (f) Levye, (g) Cyayı, (h) Ayar cıvataları, (i) İtici pimler, (j) Ayar mekanizması alt parçaları. 


\section{Orijinal Tork Plakası SE Analizleri}

Orijinal tork plakasının SE analizleri için, Catia V5R19 yazılımı ile modellenen Şekil 2(a)'daki üç boyutlu (3B) katı model ANSYS Mechanical 19.2 yazılımına aktarılmıştır. SE ağ yapısı için tüm yüzeylere $3 \mathrm{~mm}$ boyutunda, tetrahedral yapıda elemanlar tanımlanmıştır. 329.180 düğüm noktası ve 191.861 elemandan oluşan SE modeli Şekil 2(b)'de verilmektedir. Tork plakası malzemesi olarak GGG50 (EN-GJS-500) küresel grafitli dökme demir tercih edilmiştir. Fiziki döküm tork plakası üzerinden çıkarılan deney numuneleri ile gerçekleştirilen çekme deneyi verilerinden yararlanılarak multilineer GGG50 malzeme modeli oluşturulmuştur. Şekil 2(c)'de GGG50 malzemesine ait deneysel gerilme - plastik şekil değiştirme eğrisi verilmektedir. Diğer GGG50 malzeme özellikleri Tablo 1 altında verilmektedir.
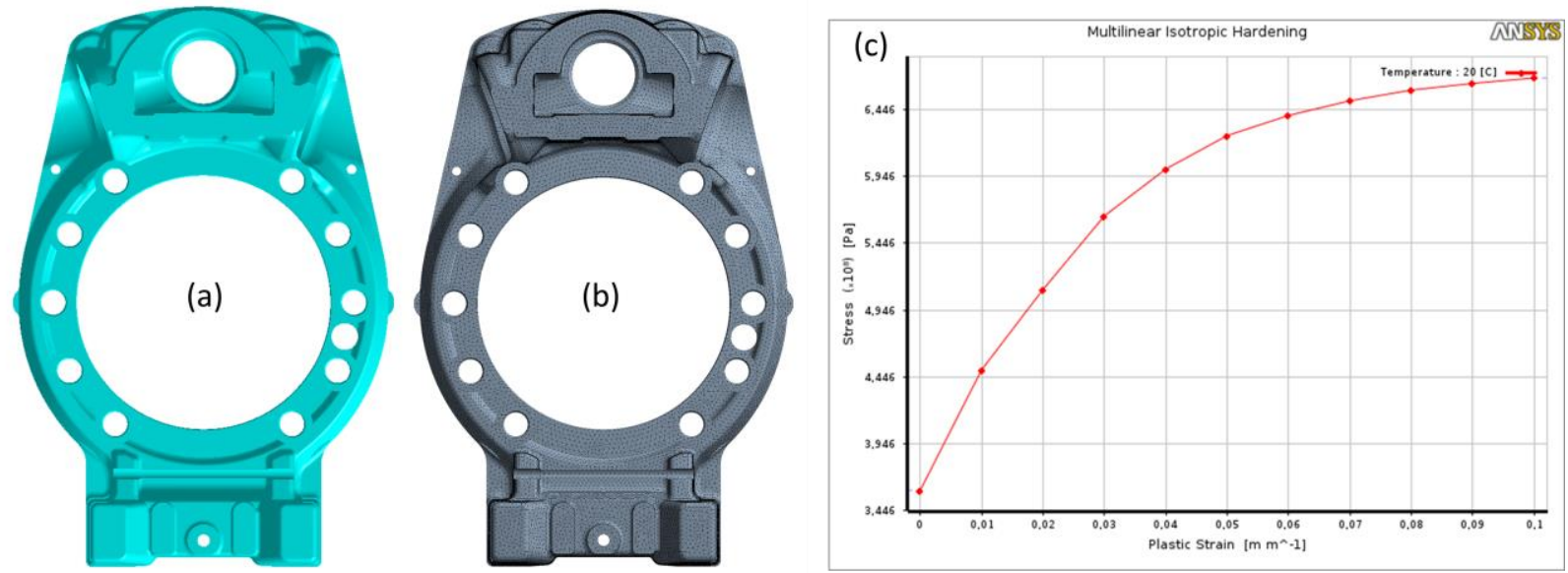

Şekil 2. (a) Orijinal tork plakası (a) 3B katı modeli, (b) sonlu elemanlar modeli ve (c) GGG50 gerilme - plastik şekil değiştirme eğrisi.

Tablo 1. GGG50 malzeme özellikleri.

\begin{tabular}{lc}
\hline Malzeme Özellikleri & \\
\hline Young Modülü [GPa] & 170 \\
Poisson Oranı [-] & 0.29 \\
Akma Gerilmesi [MPa] & 360 \\
Yoğunluk [kg/m $\left.{ }^{3}\right]$ & 7300 \\
\hline
\end{tabular}

Orijinal tork plakası maksimum $20 \mathrm{kNm}$ fren torku $\left(\mathrm{T}_{\mathrm{b}}\right)$ için tasarlanmıştır. Bu hizmet koşulu için SE analizlerinin ilk adımında, tork plakasına etkiyen reaksiyon kuvvetleri tork plakası üzerindeki mil yatak yüzeyine, yaslanan ve karşılayan pabuçların mesnet yüzeylerine uygulanmıştır (Şekil 4(a)). Yaslanan ve karşılayan pabuçlara ait reaksiyon kuvvetlerinin belirlenmesi için vektör analizi gerçekleştirilmiştir. Hesaplamalarda, balata ve kampana arasındaki sürtünme katsayısı $\mu=0,37$ olarak kabul edilmiştir. Şekil 3 'te yaslanan ve karşılayan pabuçlara ait serbest cisim diyagramları verilmektedir. Burada tanjant kuvvetler $\mathrm{F}_{\mathrm{T} 1-2}$, normal yöndeki kuvvetler $\mathrm{F}_{\mathrm{N} 1-2}$, pabuç mesnet kuvvetleri $\mathrm{F}_{\mathrm{A} 1-2}$ ve ayar c1vatalarının uyguladığ piston kuvvetleri $\mathrm{F}_{\mathrm{P} 1-2}$ ile ifade edilmektedir.

Yatay ve düşeydeki kuvvet eşitliği göz önünde bulundurularak elde edilen matematiksel ifadeler;

$F_{N 1 x}-F_{P 1 x}-F_{A 1 x}=0$

$F_{A 1 y}-F_{T 1 y}-F_{P 1 y}=0$ 
$F_{P 2 x}+F_{A 2 x}-F_{N 2 x}=0$

$F_{A 2 y}+F_{T 2 y}-F_{P 2 y}=0$

Q1 ve Q2 noktalarının moment eşitliğinden faydalanılarak elde edilen matematiksel ifadeler;

$F_{N 1 .} r_{N 1}-F_{T 1} . r_{T 1}-F_{P 1} . r_{P 1}=0$

$F_{P 2} . r_{P 2}-F_{T 2} \cdot r_{T 2}-F_{N 2} \cdot r_{N 2}=0$

Burada;

$F_{T 1-2}=T_{b} /\left(2 \cdot r_{d r u m}\right)$
$F_{N 1-2}=F_{T 1-2} / \mu$

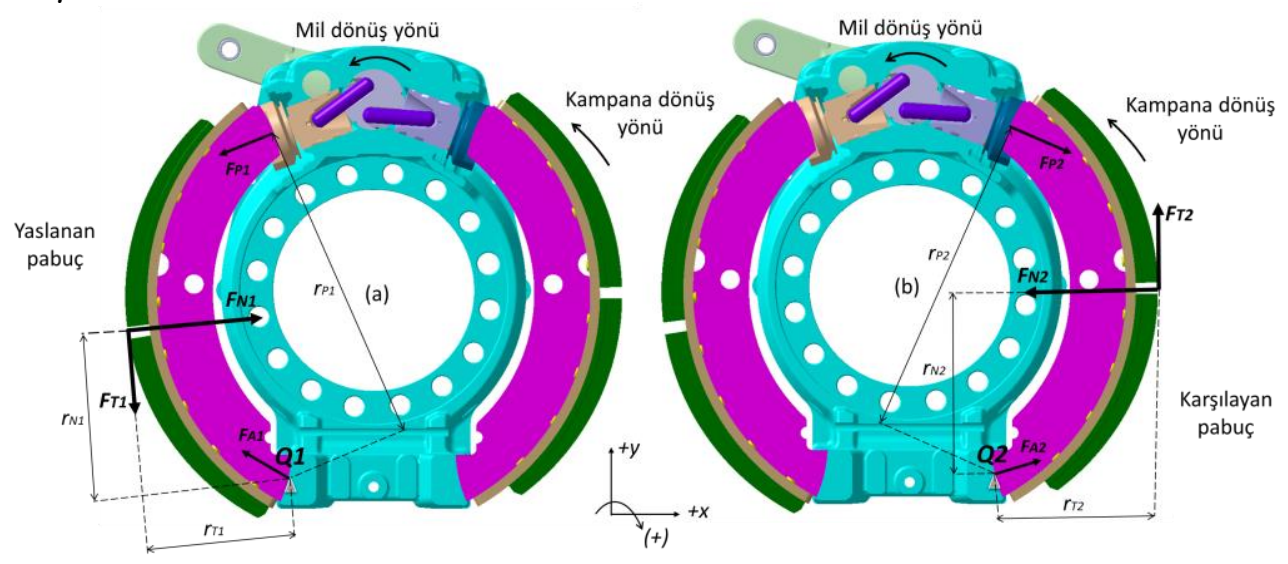

Şekil 3. Pabuçlara etkiyen kuvvetler (a) Yaslanan pabuç, (b) Karşılayan pabuç.

Hesaplanan reaksiyon kuvvetleri Tablo 2'de verilmektedir. Ayrıca tork plakası, aks bağlantı deliklerinden sabit mesnet sınır koşulu ile sabitlenmiştir.

Tablo 2. Tork plakasina etkiyen reaksiyon kuvvetleri.

\begin{tabular}{lc}
\hline Reaksiyon kuvvetleri [N] & \\
\hline Mil yatak kuvveti - Yaslanan pabuç tarafi $\left(\mathrm{F}_{\mathrm{P} 1}\right)$ & 48864 \\
Mil yatak kuvveti - Karş1layan pabuç tarafi $\left(\mathrm{F}_{\mathrm{P} 2}\right)$ & 87344 \\
Pabuç mesnet kuvveti - Yaslanan pabuç $\left(\mathrm{F}_{\mathrm{A} 1}\right)$ & 117910 \\
Pabuç mesnet kuvveti - Karşılayan pabuç $\left(\mathrm{F}_{\mathrm{A} 2}\right)$ & 35175 \\
\hline
\end{tabular}

Tork plakası için en kritik yükleme durumu kasisli yollarda frenleme sırasında meydana gelmektedir. Bu nedenle, hizmet kuvvetlerine ek olarak 2. analiz adımında fren körüğü, braket, levye ve mil parçalarının tork plakasına ilettiği titreşim yükleri uygulanmıştır. Bunun için, her bir parçanın ağırlık merkezinin bulunduğu koordinatlardan tork plakasına kuvvet iletimini gerçekleştirdikleri braket bağlantı arayüzünden titreşim yükleri uygulanmıştır. Saha tecrübelerinden yola çıkılarak, titreşim nedeniyle açığa çıkan maksimum ivmenin büyüklüğü $30 \mathrm{~g}$ olarak belirlenerek, titreşim yükü hesabında dikkate alınmıştır (g: yer çekimi ivmesi). Şekil 4(b)'de 2. analiz adımında tork plakasına uygulanan titreşim kuvvetleri verilmektedir.

Yukarıda detayları paylaşılan 2 analiz adımına ek olarak, tork plakasının diğer akson veya aks flanşına bağlantı oryantasyonlarının simülasyonu için 8 farklı analiz adımı tanımlanmıştır. Bu amaçla, titreşim yüklerinin doğrultusu her bir analiz adımında $10^{\circ}$ döndürülmüştür. Şekil 4(c)'de 
diğer analiz adımlarında tork plakasına uygulanan, doğrultusu $10^{\circ}$ döndürülmüş titreşim kuvvetleri verilmektedir.

SE analizleri sonucunda, orijinal tork plakası için toplam deformasyon, von-Mises ve maksimum asal gerilme dağılımları elde edilmiştir (Şekil 5(a)-(c)). Analiz sonuçları 1şığında tork plakası üzerindeki kritik gerilme bölgeleri belirlenerek (Şekil 5(d)), bu bölgelerdeki gerilme değerleri Tablo 3'de özetlenmiştir.

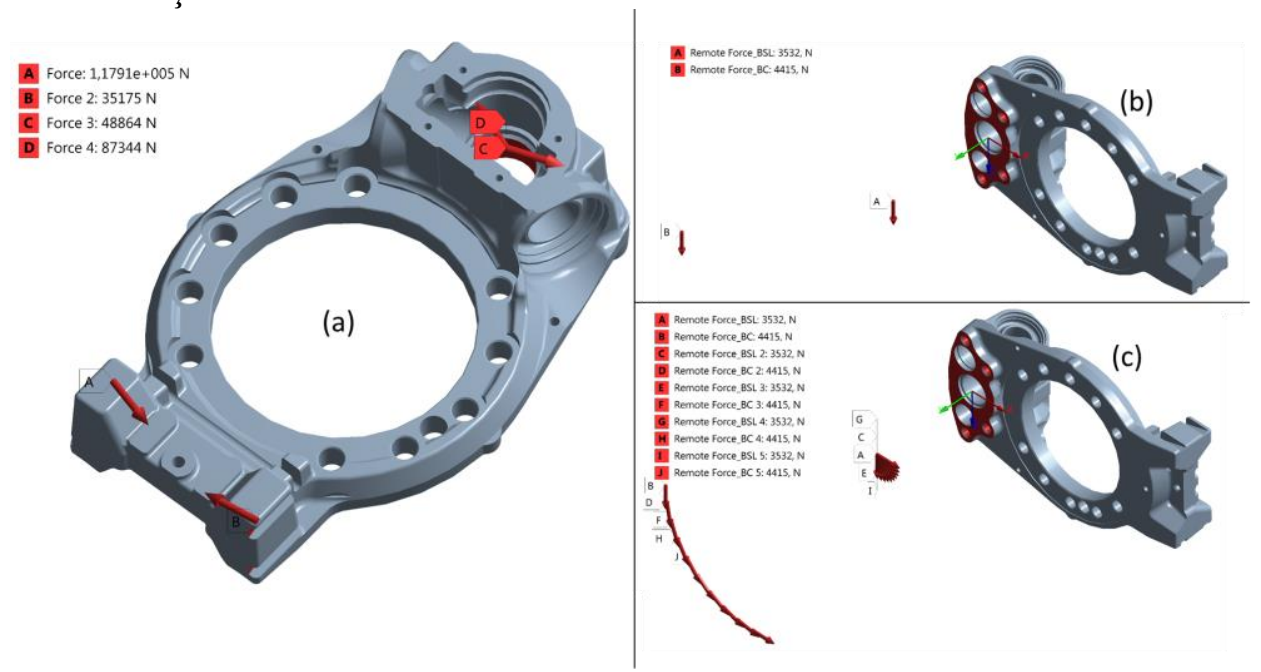

Şekil 4. Sınır koşulları (a) 1. analiz adımı, (b) 2. analiz adımı, (c) Diğer analiz adımları.
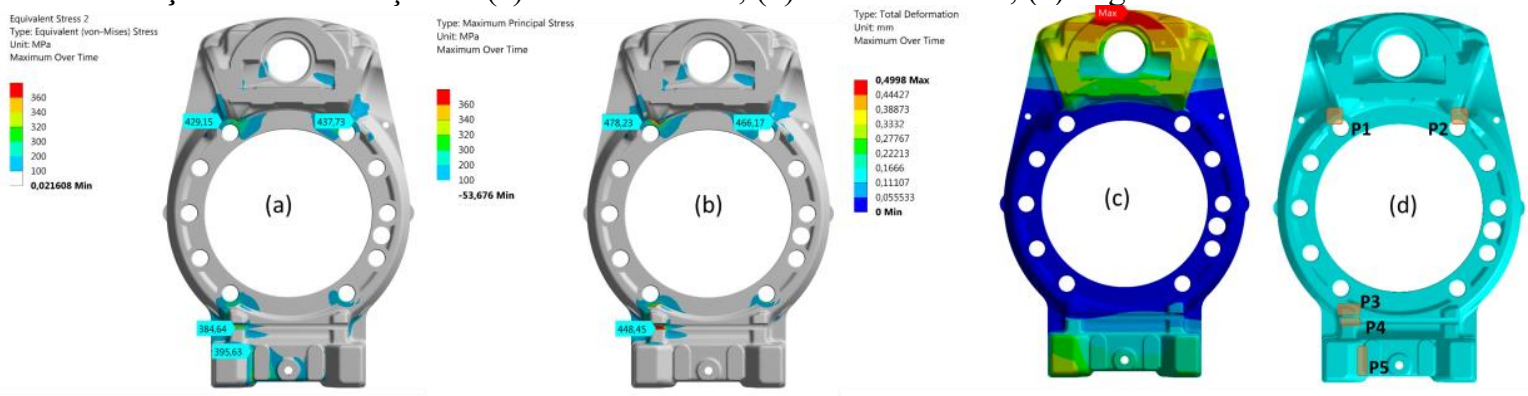

Şekil 5. Orijinal tork plakası SE analiz sonuçları. (a) von-Mises gerilme (MPa), (b) Maksimum asal gerilme (MPa), (c) Toplam deformasyon (mm), (d) Kritik gerilme bölgeleri.

\section{Topoloji Optimizasyonu ve Doğrulama Analizleri}

Topoloji optimizasyonu amacıyla, ilk önce $3 \mathrm{~mm}$ eleman boyutu tanımlanmış orijinal tork plakasının SE analizleri önceki bölümde detayları verilen sınır koşulları altında gerçekleştirilir. Bundan sonra, topoloji optimizasyonu aşamas1, ANSYS 19.2 SE ve topoloji optimizasyonu modülleri arasında ilişki oluşturarak başlar.

Optimizasyon için tanımlanan parametreler şunlardır:

- Tasarım bölgesi (Designable region): Bu bölge malzemenin ekleneceği veya çıkarılacağı maksimum kullanılabilir hacimdir. Tork plakası için tasarım bölgesi Şekil 6(a)'da mavi belirtilen yüzeylerdir. 
- Çıkarılan bölge (Exclusion region): Bu bölge model üzerinde değiştirilmesi istenmeyen alanları belirtir. Tork plakası için tüm işlenmiş yüzeyler, tüm montaj, sabitleme yüzeyleri ve delikleri çıkarılan bölge olarak tanımlanmıştır. Çıkarılan bölge Şekil 6(a)'da kırmızı ile belirtilen yüzeylerdir.

- Üretilebilirlik sınırları: Döküm kalıbı açılma yönü (Şekil 6(b)) ve 7 mm minimum cidar kalınlığı tanımlanmıştır.

- Optimizasyon hedefi: Minimum hacimde maksimum direngenliğin elde edebilmesi için parça ağırlığının \% 30 oranında azaltılması optimizasyon hedefi olarak tanımlanmıştır.

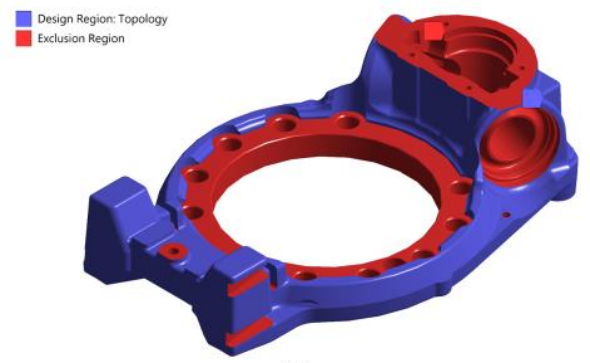

(a)

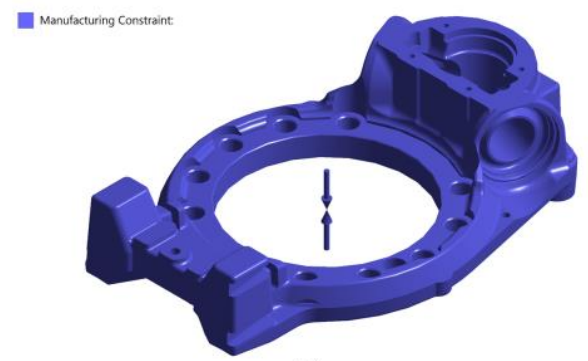

(b)

Şekil 6. Topoloji parametreleri (a) Tasarım ve çıkarılan bölgeler, (b) Kalıp açılma yönü.

Topoloji optimizasyonunun çıktısı topoloji yoğunluğudur. Her bir eleman için $0-1$ arasında bir yoğunluk değeri verilmektedir. Topoloji yoğunluğu yüksek olan elemanlar direngenliği sağlayan bir diğer değişle yapıda tutulması gerekli elemanlar olup, düşük yoğunluklu elemanların yapıdan çıkarılması ağırlık indirgemesi açısından tasarımcıya fikir vermektedir [17]. Şekil 7'de 0,4 ve üzeri yoğunluğa sahip elemanlar verilmektedir. Optimizasyon sonucunda elde edilen bu ham çözüm (Şekil 7), tork plakasının nihai, optimize edilmiş tasarımını elde etmek için ANSYS topoloji optimizasyonu modülünden Catia V5R19'a aktarılır. Tasarım değişikliği ve SE analizi adımları, döküm ve işleme prosesleri göz önüne alınarak tekrarlanır. Orijinal tasarımdan final tasarımın elde edilmesi için gerçekleştirilen tasarım değişikliği adımları Şekil 8'de 1-5 arasında verilmektedir. Şekil 8'de turkuaz ile gösterilen geometri orijinal tasarımı; sarı ile gösterilen geometri final tasarımını belirtmektedir. Final tasarımın doğrulanması amacıyla, SE analizleri gerçekleştirilmiştir. Final tasarıma ait toplam deformasyon, von-Mises ve maksimum asal gerilme dağılımları Şekil 9'da verilmektedir.
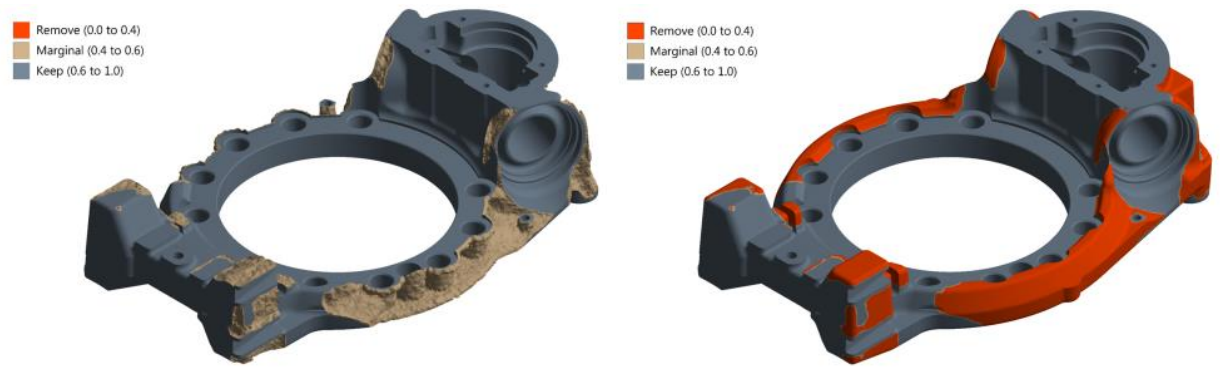

Şekil 7. Topoloji yoğunluğu dağılımı.

\section{Bulgular ve Tartışma}

Tablo 3'de her iki tork plakasının SE analizi sonuçları karşılaştırılmaktadır. Von-Mises gerilme 
sonuçları değerlendirildiğinde, final tasarıma ait gerilmelerin P3 dışında tüm kritik lokasyonlarda $\%$ 4,3 - 12,3 oranında azaldığı görülmektedir. Maksimum asal gerilme sonuçlarından, final tasarıma ait gerilmelerin P3 dışında tüm kritik lokasyonlarda \% 0,6 - 17,2 oranında azaldığı görülmektedir. P3 lokasyonunda, von-Mises ve maksimum asal gerilmelerdeki \% 1,4 ve \% 4,9 oranındaki artış, orijinal tork plakasındaki maksimum gerilme değerleri göz önünde bulundurulduğunda kabul edilebilir mertebededir.

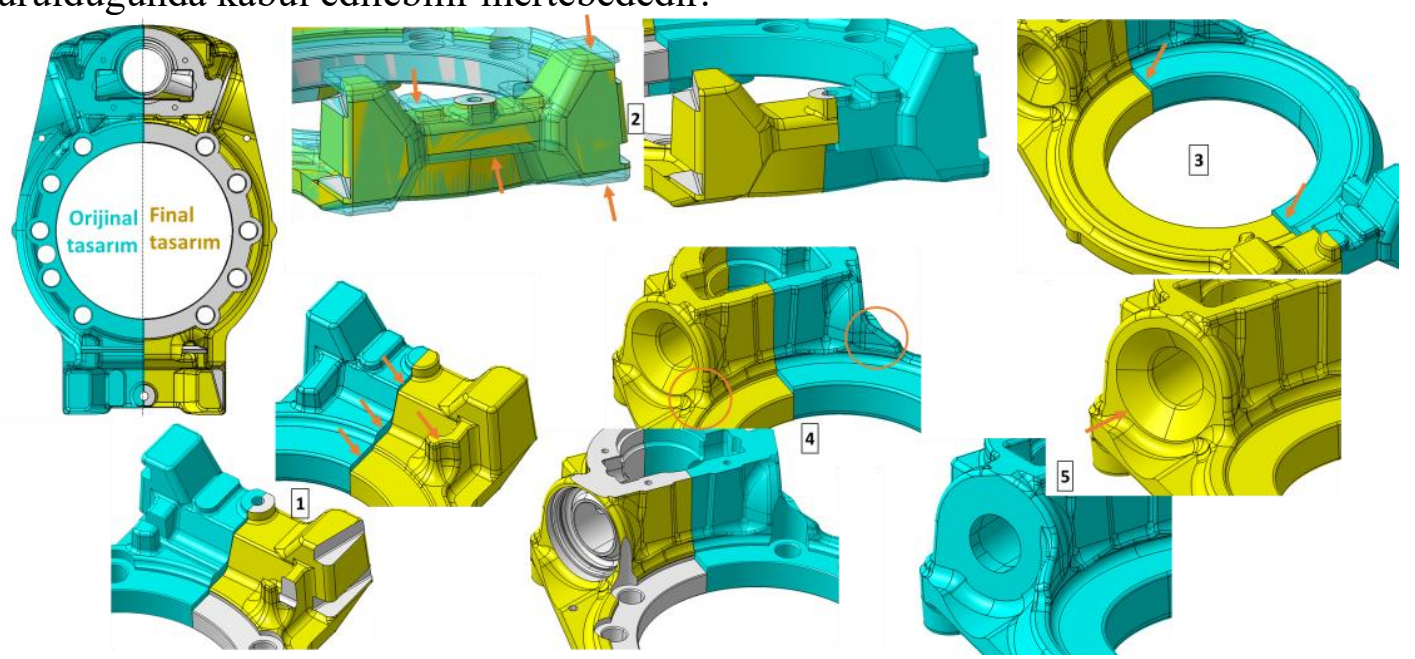

Şekil 8. Tasarım değişiklikleri.
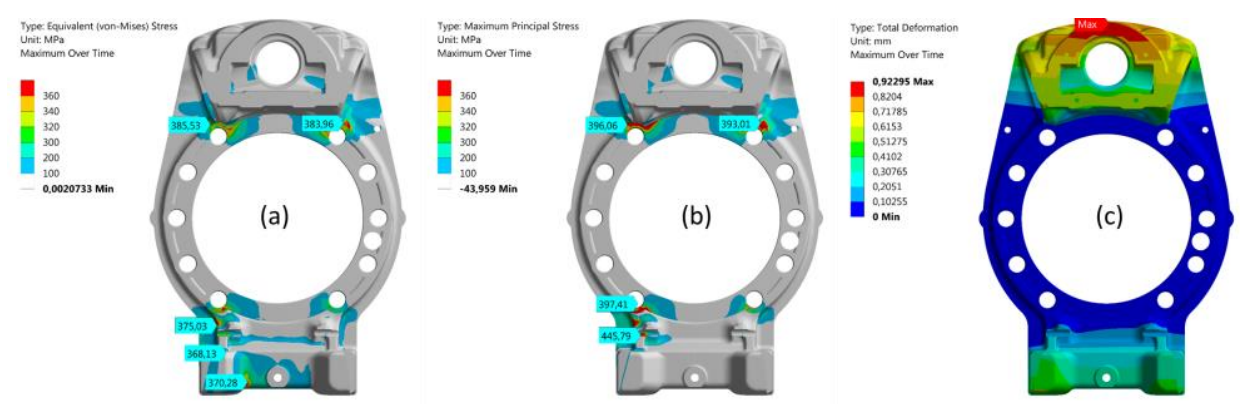

Şekil 9. Final tasarıma ait analiz sonuçları (a) von-Mises gerilme (MPa), (b) Maksimum asal gerilme (MPa), (c) Toplam deformasyon (mm).

Final tasarıma ait maksimum deformasyon değerleri, 1. ve son analiz adımları için sırasıyla \% 66,6 ve $\% 85,0$ artmıştır. Buna karşılık, 1. analiz adımındaki maksimum deformasyon orijinal tasarımda 0,311 mm iken, final tasarımda $0.518 \mathrm{~mm}$ 'dir. Deformasyon farkı oldukça düşük olduğu için, bu artışın fren çalışmasını ve başarımını olumsuz yönde etkileyemeyeceği beklenmektedir. Diğer taraftan, maksimum deformasyon final tasarımda \% 85,0 oranında artmıştır. Bu deformasyon miktarının Z-kam kampanalı fren alt parçaları arasında girişime neden olmayacağı göz önünde bulundurularak, kabul edilebilir olduğu düşünülmektedir. Ayrıca, tork plakası servis ömrü boyunca titreşim ve hizmet yüklerinin kombinasyonundan ziyade, tekil hizmet yüklerine maruz kalmaktadır. Ancak toplam deformasyondaki artışın, gürültü-ses-konfor açısından deneysel olarak araştırılması gereklidir.

Her iki tasarıma ait döküm ve işleme parça ağırlıkları değerlendirildiğinde, final tasarımda 1,877 $\mathrm{kg}$ ile \% 11,9 oranında bir ağırlık indirgemesi elde edilmiştir. Ayrıca final tasarım, işleme parça 
ağırlığı 1,497 kg ile \% 12,2 oranında bir ağırlık optimizasyonu sunmaktadır.

Tablo 3. Orijinal ve final tasarımlara ait SE analiz sonuçları.

\begin{tabular}{c|ccccc|cccc|ccc}
\hline & \multicolumn{4}{|c|}{ von-Mises Gerilme [MPa] } & \multicolumn{3}{c|}{ Maksimum Asal Gerilme [MPa] } & \multicolumn{3}{c}{$\begin{array}{c}\text { Toplam } \\
\text { Deformasyon } \\
\text { [mm] }\end{array}$} \\
\cline { 2 - 13 } & P1 & P2 & P3 & P4 & P5 & P1 & P2 & P3 & P4 & 1. adım & Maks. \\
\hline $\begin{array}{c}\text { Orijinal } \\
\text { tasarım }\end{array}$ & 429.2 & 437.7 & 369.8 & 384.6 & 395.6 & 478.2 & 466.2 & 378.8 & 448.5 & 0.311 & 0.499 \\
\hline Final tasarım & 385.5 & 384.0 & 375.0 & 368.1 & 370.3 & 396.1 & 393.0 & 397.4 & 445.8 & 0.518 & 0.923 \\
\hline Fark [\%] & -10.2 & -12.3 & +1.4 & -4.3 & -6.4 & -17.2 & -15.4 & +4.9 & -0.6 & +66.6 & +85.0 \\
\hline
\end{tabular}

Tablo 4. Ağırlık kıyaslaması.

\begin{tabular}{lcc}
\hline & Döküm parça ağırlı̆̆ $[\mathrm{kg}]$ & İşleme parça ağıllığ $[\mathrm{kg}]$ \\
\hline Orijinal tasarım & 15.752 & 12.235 \\
Final tasarım & 13.875 & 10.738 \\
\hline \multirow{2}{*}{ Ağırlık indirgemesi } & 1.877 & 1.497 \\
& {$[11.9 \%]$} & {$[12.2 \%]$} \\
\hline
\end{tabular}

\section{Sonuçlar}

Bu çalışmada, ağır hizmet araçlarında kullanılan Z-kam kampanalı frenin ana parçası olan tork plakasının mekanik tasarımı konu edilmiştir. Ağıllık indirgemesi amacıyla, topoloji optimizasyonu ve SE yöntemlerinin kullanıldığı bir simülasyon modeli önerilmiştir. İlk olarak, kritik gerilme bölgelerinin ve seviyelerinin tespiti için orijinal tork plakasının SE analizi gerçekleştirilmiştir. Daha sonra, belirlenen sınır koşulları altında orijinal tork plakasının topoloji optimizasyonu gerçekleştirilmiştir. İhtiyaç duyulmayan hacimler ve üretilebilirlik kısıtlamaları göz önünde bulundurularak yeni bir tork plakası tasarımı oluşturulmuştur. Son olarak, final tasarımın doğrulanması için SE analizleri tekrarlanmıştır.

Çalışmanın nihai sonucu olarak, her iki tasarımın SE analiz sonuçları karşılaştırıldığında, gerilme seviyelerindeki belirgin düşüşe ek olarak, döküm ve işlenmiş parça ağırlıklarında sırasıyla \% 11,9 ve $\% 12,2$ azalma sağlanmıştır.

Sonraki araştırmalarda, kampanalı fren kütlesinin diğer kısmını oluşturan pabuç ve braket tasarımlarının, bu çalışma kapsamında önerilen ağırlık optimizasyonu sistematiği kullanılarak geliştirilmesi önerilmektedir.

\section{Referanslar}

[1] Limpert, R. Brake design and safety, SAE, 1992.

[2] Güleryüz, İ. C. Modelling, Analysis and Experimental Verification of Pneumatic Brake System. MSc Thesis, Izmir Katip Celebi University, TR, 2017. 
[3] Day, A. J. Braking of road vehicles. Butterworth-Heinemann, 2014.

[4] Reif, K. Brakes, Brake control and driver assistance systems. Weisbaden, Germany, Springer Vieweg, 2014.

[5] Sayim, I. and Zhang, D. Optimization of the brake factor for an S-Cam foundation brake using RSM/Optimizacija zavornega faktorja pri bobnastih zavorah z S-odmikalom po metodi odzivne povrsine. Strojniski Vestnik-Journal of Mechanical Engineering, 2016; 62.9: 503511.

[6] Hecht Basch, R., Fash, J., Hasson, R., et al. Initial dynamometer and laboratory evaluations of thermally sprayed aluminium brake disc. Barton D, Earl S, Brakes, 2000; 11-12.

[7] Sergent, N., Tirovic, M. and Voveris, J., Design optimization of an opposed piston brake caliper. Engineering Optimization, 2014; 46.11: 1520-1537.

[8] Mathur, A. and Kurna, S. Weight optimization of Axle Beam using Optistruct, In: Altair Technology Conference, India, 2015.

[9] Topac, M. M. and Atak, M. Optimal design of a rigid front axle beam for trucks, In: 1st International Mediterranean Science and Engineering Congress (IMSEC 2016), Çukurova University, Congress Center, Adana/Turkey, October 26-28 2016, paper no. 453.

[10] Topac, M. M., Kuralay, N. S. and Bahar, I. Mass and Stress Optimisation of a Multi-Purpose Vehicle Front Axle Differential Housing For Various Driving Conditions, Duzce University Journal of Science \& Technology, 2016; 4: 501-513.

[11] Topac, M. M., Bahar, E., Kaplan, A., et al. Design of a lower wishbone for a military vehicle independent front suspension using topology optimization. In IDEFIS 2017: 2nd International Defence Industry Symposium, 2017, pp.333-342.

[12] Yücel, U., Yılmaz, B., Güleryüz, İ. C., et al. A back-plate weight optimization of a heavyduty s-cam drum brake, In: International Mechanical Engineering and Technologies Conference Proceedings (MECHATECH'16), May 17-18 2016, Istanbul/Turkey, pp.218235.

[13] Güleryüz, İ. C., Y1lmaz, B., Lightweight design of a torque plate of Z-cam drum brake for heavy duty vehicles. International Journal of Automotive Science and Technology, 2019, 3.2: $42-50$.

[14] Zhang, Y., Zhang, H., and Lu, C. Study on parameter optimization design of drum brake based on hybrid cellular multiobjective genetic algorithm. Mathematical Problems in Engineering, 2012; 734193.

[15] Ragothaman, G., Krishnan, R. A., Balamurugan, A., et al. Design and Analysis of SCamshaft And Torque Plate, International Journal of Pure and Applied Mathematics, 2018; 119.12: 13515-13522.

[16] Kuralay, N. S. Motorlu Taşıtlar; Temel ve Tasarım Esasları, Yapı Elemanları, Izmir: TMMOB Makina Mühendisleri Odası, 2008.

[17] Johnsen, S. Structural topology optimization: basic theory, methods and applications. MSc Thesis, Institutt for produktutvikling og materialer, 2013. 